\title{
Exergy Analysis of Metal Oxide Carbothemic Reduction under Vacuum - Sustainability prospects
}

\author{
E. Balomenos*, D. Panias, I. Paspaliaris \\ National Technical University of Athens \\ Laboratory of Metallurgy \\ 9, Heroon Polytechneiou str., 157 73, Zographou Campus, Greece \\ * Corresponding author, email: thymis@ metal.ntua.gr
}

\begin{abstract}
Based on the fundamental Le Chatellier principle, gas producing reactions can be pushed at lower temperatures if an appropriate vacuum is applied. A basic thermodynamic analysis is used to predict the effect of pressure decrease on the temperature and exergy cost of a reaction with gaseous products. The energy analysis of 11 different metal producing carbothermic reductions revealed that the pumping work substitutes relatively the same amount of heat in all 11 reactions, despite the fact that the volume of gases evolved in each case differs significantly. The exergy analysis for conducting these reactions with non-renewable resources showed that due to the high exergy cost of fossil fuel generated electricity the application of vacuum would increase the overall exergy cost of these reductions. If the heat needed for the reactions could be produced through renewable resources, such as concentrated solar radiation, then the use of vacuum would have a positive effect in the cases of high temperature reductions of $\mathrm{Al}_{2} \mathrm{O}_{3}$, $\mathrm{MgO}$ and $\mathrm{CaO}$, where a significant decrease in reaction temperature is observed as more exergy is spent in pumping work.
\end{abstract}

\section{Keywords: Exergy, Vaccum Metallurgy, Carbothermic reduction, Solar furnaces}

\section{Introduction}

Metallurgical processing under vacuum was firstly used during the first World War in Germany in order to degas and purify steel and nickel-chrome alloys (Kroll, 1951). Since then vacuum has been applied in processes

- requiring protection of a metal bath from oxidation, nitriding or from process produced gases (e.g. hydrogen)

- of metal purification and separation of alloys through selective volitization of elements

- for dissociation of inorganic oxides which can undergo thermal decomposition in solid and gaseous components

- of metal oxide reductions from less volatile reducing agents (e.g. silicon or carbon), where the metal is usually produced in the gaseous phase and is recovered through condensation.

The latter two cases refer to metallurgical processes usually achievable at moderate or high temperatures under atmospheric pressure, which when conducted under vacuum can occur at significantly lower temperatures. This is due to the fundamental Le Chatellier principle which when applied in gas producing reactions, states that the extent of the reaction will be increased as the pressure is reduced. If these reactions take place at a temperature higher than that of the environment, then lowering the total pressure will result in lowering of the temperature needed for the reaction to occur. Practically this means that one can substitute part of the process heat needed for an endothermic reaction with pumping work and conduct the process at lower temperatures. While the overall energy needed for the reaction is not reduced, the prospect of utilizing concentrated solar radiation for providing process heat (Murray, Steinfeld, Fletcher, 1995) has renewed interest in using vacuum as a way of reducing reaction's temperature to levels attainable in solar furnaces (Kruesi, Galvez, Halmann, Steinfeld, 2011). In the present paper a theoretical investigation of the exergy cost related to process heat and vacuum production is made for a group of characteristic metallurgical reactions.

\section{Thermodynamic analysis}

For any chemical reaction to occur an amount of enthalpy $(\Delta \mathrm{H})$, also known as heat of reaction, must be absorbed or released by the system in such conditions that the total chemical work of the system is negative or zero. The conditions mentioned refer to the intensive parameters of the system namely temperature, pressure and chemical potential. As known for a system under constant temperature and pressure its chemical work is expressed by the Gibbs free energy potential $(\Delta \mathrm{G})$ and the criteria for it being in a state of thermodynamic equilibrium is

$\Delta \mathrm{G}^{(\mathrm{T}, \mathrm{P})} \leq 0$

The changes in the Gibbs free energy potential are connected with enthalpy and entropy changes in the system according to

$\Delta \mathrm{G}^{(\mathrm{T}, \mathrm{P})}=\Delta \mathrm{H}^{(\mathrm{T}, \mathrm{P})}-\mathrm{T} \Delta \mathrm{S}^{(\mathrm{T}, \mathrm{P})}$

A reaction which at environmental conditions $\left(\mathrm{T}_{\mathrm{o}}, \mathrm{P}_{\mathrm{o}}\right)$ has a positive $\Delta \mathrm{H}^{\mathrm{o}}$ and a positive $\Delta \mathrm{G}^{\mathrm{O}}$ requires in order to take place the absorption of $\Delta \mathrm{H}^{\mathrm{o}}$ Joules of heat which will be converted into $\Delta \mathrm{G}^{0}$ Joules of chemical work. Since this is essentially a heat transfer phenomenon, the temperature 
of the heat reservoir supplying the $\Delta \mathrm{H}^{0}$ Joules of heat is crucial. Assuming that the thermodynamic functions $\Delta H$ and $\Delta S$ are practically invariant with temperature ${ }^{a}$, then as the temperature rises the heat dissipation term $\mathrm{T} \Delta \mathrm{S}$ increases until the point where Eq. 1 is satisfied and the reaction takes place. Thus practically at $\mathrm{T}$ where $\Delta \mathrm{G}^{\mathrm{T}}=0$

$\Delta \mathrm{G}^{\mathrm{o}}-\Delta \mathrm{G}^{\mathrm{T}}=\left(\Delta \mathrm{H}^{\mathrm{o}}-\mathrm{T}_{\mathrm{o}} \Delta \mathrm{S}^{\mathrm{o}}\right)-\left(\Delta \mathrm{H}^{\mathrm{T}}-\mathrm{T} \Delta \mathrm{S}^{\mathrm{T}}\right)=\Delta \mathrm{S}^{\mathrm{o}}\left(\mathrm{T}-\mathrm{T}_{\mathrm{o}}\right)$

If the entropy change $\Delta S^{0}$ is associated with a heat transfer of Q Joules at T temperature then

$\Delta \mathrm{G}^{\mathrm{o}}=(\mathrm{Q} / \mathrm{T})\left(\mathrm{T}-\mathrm{T}_{\mathrm{o}}\right)=\mathrm{Q}\left(1-\mathrm{T}_{\mathrm{o}} / \mathrm{T}\right)$

Eq. 4 is of course the maximum achievable work for a heat engine operating between the heat reservoirs $\mathrm{T}$ and $\mathrm{T}_{\mathrm{o}}<\mathrm{T}$. Thus depending on the choice of the standard reference states the Gibbs free energy potential of the system can be equated with the chemical exergy of the system $(\Delta \mathrm{E})[0]$, denoting the portion of the heat of the reaction $\mathrm{Q}=\Delta \mathrm{H}^{\mathrm{o}}$ which will be utilized as chemical work, while the remaining $T_{0} \Delta S^{0}$ will be dissipated as irreversible heat $\left(\mathrm{Q}_{\text {irr }}\right)$. Thus

$\Delta \mathrm{E}=\mathrm{Q}-\mathrm{Q}_{\text {irr }}=\Delta \mathrm{H}^{\mathrm{o}}\left(1-\mathrm{T}_{\mathrm{o}} / \mathrm{T}\right)=\Delta \mathrm{G}^{\mathrm{o}}=\mathrm{W}_{\mathrm{q}}$

where $\mathrm{W}_{\mathrm{q}}$ denotes the work that must be absorbed by the system through heating.

From Eq. 5 one can calculate the temperature of the heat reservoir supplying the heat of the reaction according to

$$
\mathrm{T}=\mathrm{T}_{\mathrm{o}} /\left[1-\left(\Delta \mathrm{E} / \Delta \mathrm{H}^{\mathrm{o}}\right)\right]
$$

The ratio $\lambda=\Delta \mathrm{E} / \Delta \mathrm{H}^{\mathrm{o}}$ (slope of the exergy-enthalpy vector of the reaction) is a measure of the availability of energy of the reaction (Sato, 2004). The temperature calculated in Eq. 6 would be valid given the assumption mentioned earlier, that the enthalpy and entropy changes of the reaction are constant through-out the temperature region $\mathrm{T}_{\mathrm{o}}-\mathrm{T}$. It is therefore an approximation and not an exact calculation, but still useful for the discussion of the present work.

Returning to the case of a reaction with gaseous products which occurs at a pressure $\mathrm{P}<\mathrm{P}_{0}$, if one assumes that the pressure is reduced through an isothermal expansion of the gases (assumed to be ideal), then the work done against the atmospheric pressure is given by

$\mathrm{W}_{\mathrm{p}}=\mathrm{n} \mathrm{R} \mathrm{T} \ln \left(\mathrm{P}_{0} / \mathrm{P}\right)$

where $\mathrm{R}$ is the universal gas constant, $\mathrm{n}$ is the total number of gaseous moles which undergo the isothermal expansion at temperatureT.

During this isothermal expansion if no phase change occurs and therefore the internal energy of the system remains constant, in accordance with the first law of thermodynamics, all the work described in Eq. 7 will be

\footnotetext{
${ }^{a}$ This implies that no phase changes occur as the temperature increases and that $\mathrm{C}_{\mathrm{p}}$ coefficients of reactants and products are invariant of temperature. The first assumption would be true if one chooses correctly the phases of the reactants at $\left(\mathrm{T}_{0}, \mathrm{P}_{\mathrm{o}}\right)$ and the phases of the products at $(\mathrm{T}, \mathrm{P})$ where the reaction takes place. The second assumption is obviously false; however the temperature dependence of the $\mathrm{Cp}$ coefficients is usually small and therefore can be omitted in a "crude" approximation.
}

converted to heat dissipated in the system. This is equivalent with stating that the work done to the system is used to increase the entropy related to the compressible phases of the system, as they can now occupy more space at the same temperature. Thus one can define the entropy increase due to pumping,

$\Delta \mathrm{S}_{\mathrm{p}}=\mathrm{Q}_{\mathrm{p}} / \mathrm{T}=\mathrm{W}_{\mathrm{p}} / \mathrm{T}=\mathrm{n} \mathrm{R} \ln \left(\mathrm{P}_{\mathrm{o}} / \mathrm{P}\right)$

Returning to equation (3), the exergy change of the system undergoing a chemical reaction from an initial state $\left(\mathrm{T}_{\mathrm{o}}, \mathrm{P}_{\mathrm{o}}\right)$ to the final state $(\mathrm{T}, \mathrm{P})$ is given by

$$
\Delta \mathrm{E}^{*}=\Delta \mathrm{H}^{\mathrm{o}}-\mathrm{Q}_{\text {irr }}-\mathrm{W}_{\mathrm{p}}=\mathrm{W}_{\mathrm{q}}^{*}
$$

The heat of reaction $\Delta \mathrm{H}^{0}$ remains the same as it reflects the total energy needed to change the reactants into products. Likewise the irreversible heat losses $\mathrm{Q}_{\text {irr }}$ which are linked with the entropy change associated with the transformation of the reactants into products at $\left(\mathrm{T}_{\mathrm{o}}, \mathrm{P}_{\mathrm{o}}\right)$ will remain the same. Thus the pressure decrease reduces directly the exergy change $(\Delta \mathrm{E})$ associated with the reaction or the work that must be absorbed by the system through heating for the reaction to take place. Additionally, according to Eq. 6 the temperature at which this heating has to take place is reduced to $\mathrm{T}^{*}<\mathrm{T}$.

Therefore when conducting an endothermic gas evolving reaction one can be more resource efficient if the sum of exergy spent in pumping $\left(\mathrm{W}_{\mathrm{p}}\right)$ and in producing heat at $\mathrm{T}^{*}\left(\mathrm{~W}_{\mathrm{q}}+\mathrm{Q}_{\text {irr }}\right)$ is less than the exergy spent in producing all the heat of the reaction $(\mathrm{Q})$ at $\mathrm{T}>\mathrm{T}^{*}$.

\section{Carbothermic Reduction of metal oxides under vacuum}

A field where resource efficiency is of the outmost importance is the extractive metallurgy related with metal production from metal oxides. Oxides like hematite $\left(\mathrm{Fe}_{2} \mathrm{O}_{3}\right)$, alumina $\left(\mathrm{Al}_{2} \mathrm{O}_{3}\right)$, magnesia $(\mathrm{MgO})$ or even water $\left(\mathrm{H}_{2} \mathrm{O}\right)$ can be reduced by carbon, yielding elemental phases and $\mathrm{CO}$ gases, according to the general reaction

$\mathrm{M}_{\mathrm{x}} \mathrm{O}_{\mathrm{y}}+\mathrm{yC}=\mathrm{xM}+\mathrm{yCO}$

Utilizing the Factsage 6.1 Software the enthalpy, entropy and Gibbs free energy potential changes are calculated for the carbothermic reduction of different oxides at environmental conditions $(298.15 \mathrm{~K}, 1 \mathrm{~atm})$ as well as at lower pressures and are presented in the first five columns of Table 1. Based on these figures the irreversible heat losses $\mathrm{Q}_{\text {irr }}{ }^{(\mathrm{To}, \mathrm{Po})}=\mathrm{T}_{0} \Delta \mathrm{S}^{0}$ (where $\mathrm{T}_{0}=298.15 \mathrm{~K}$ and $\mathrm{P}_{0}=1$ atm) are calculated in column 6 while the ratio $\lambda$ and the temperature $\mathrm{T}$ of the heat reservoir needed to provide the heat of the reaction (Eq. 6) are calculated in columns seven and eight. The final state of the produced metal was calculated based on temperature $\mathrm{T}$ and pressure $\mathrm{P}$. On the ninth column of Table 1 the pumping work to achieve pressure $\mathrm{P}$ at temperature $\mathrm{T}$ is calculated according to Eq. 7 . On the final column the work that must be absorbed by the system through heating $\left(\mathrm{W}_{\mathrm{q}}\right)$ at temperature $\mathrm{T}$ and pressure $\mathrm{P}$ is calculated based on Eq. 9 (column 2 minus the summation of columns 6 and 9).

The effect of pressure decrease on the reaction temperature calculated in Table 1 is shown for all reactions considered in Figure 1. 
As seen in Figure 1, these type of reactions under vacuum, can be separated according to their respective temperature regions, into high temperature carbothermic reductions (Al, $\mathrm{Ca}, \mathrm{Mg})$, moderate temperature carbothermic reductions ( $\mathrm{Na}, \mathrm{Zn}, \mathrm{Sn}, \mathrm{Ge}, \mathrm{Fe}$ ) and low temperature carbothermic reductions $\left(\mathrm{Ni}, \mathrm{H}_{2}, \mathrm{~Pb}\right)$. The pressure dependence of $\Delta \mathrm{H}, \Delta \mathrm{G}, \mathrm{W}_{\mathrm{p}}$ and $\mathrm{W}_{\mathrm{q}}$, as described in Table 1, for one element from each group, namely aluminium, iron and hydrogen, are shown in Figures 2 to 4. In Figures 5 to 7 the relevant energy distribution for the three reactions are shown, along with the total heat needed at temperature of the reaction $\mathrm{Q}(\mathrm{T})=\mathrm{W}_{\mathrm{q}}(\mathrm{T})+\mathrm{Q}_{\text {irr }}$.

Table 1: Carbothermic Reduction of Metal oxides. All values are given per kg of produced metal. (*Note: At T=2347 K and $P=1$ atm the produced Aluminum would be liquid rather than gaseous, however in order to have a uniform base for comparisons, a hypothetical gaseous final state was chosen, as at lower pressures Aluminum is gaseous ).

\begin{tabular}{|c|c|c|c|c|c|c|c|c|c|}
\hline $\mathbf{T}_{\mathbf{0}}$ & $\mathbf{P}$ & $\Delta \mathbf{H}^{(\mathbf{T o}, \mathbf{P})}$ & $\Delta \mathbf{G}^{(\mathbf{T o}, \mathbf{P})}$ & $\Delta \mathbf{S}^{(\mathbf{T o}, \mathbf{P})}$ & $\mathbf{Q}_{\text {irr }}^{(\text {To,Po) }}$ & $\lambda=\Delta \mathrm{G} / \Delta \mathrm{H}$ & $\mathbf{T}$ & $\mathbf{W}_{\mathbf{p}}^{(\mathbf{T}, \mathbf{P})}$ & $\mathbf{W}_{\mathbf{q}}^{(T, P)}$ \\
\hline $\mathrm{K}$ & Atm & MJ & MJ & $\mathrm{MJ} / \mathrm{K}$ & MJ & & $\mathrm{K}$ & MJ & MJ \\
\hline \multicolumn{10}{|c|}{$\mathrm{Al}_{2} \mathrm{O}_{3}(\mathrm{~s})+3 \mathrm{C}(\mathrm{s})=2 \mathrm{Al}(\mathrm{g})+3 \mathrm{CO}(\mathrm{g})^{*}$} \\
\hline 298.15 & $1.00 \mathrm{E}+00$ & 37.128 & 32.412 & 0.016 & 4.716 & 0.87 & 2347.44 & 0.000 & 32.412 \\
\hline 298.15 & $1.00 \mathrm{E}-01$ & 37.128 & 31.883 & 0.018 & 4.716 & 0.86 & 2110.71 & 3.744 & 28.668 \\
\hline 298.15 & $1.00 \mathrm{E}-02$ & 37.128 & 31.354 & 0.019 & 4.716 & 0.84 & 1917.35 & 6.802 & 25.610 \\
\hline 298.15 & $1.00 \mathrm{E}-03$ & 37.128 & 30.826 & 0.021 & 4.716 & 0.83 & 1756.47 & 9.347 & 23.065 \\
\hline 298.15 & $1.00 \mathrm{E}-04$ & 37.128 & 30.297 & 0.023 & 4.716 & 0.82 & 1620.47 & 11.497 & 20.915 \\
\hline 298.15 & $1.00 \mathrm{E}-05$ & 37.128 & 29.768 & 0.025 & 4.716 & 0.80 & 1504.02 & 13.339 & 19.073 \\
\hline \multicolumn{10}{|c|}{$\mathrm{Fe}_{2} \mathrm{O}_{3}(\mathrm{~s})+3 \mathrm{C}(\mathrm{s})=2 \mathrm{Fe}(\mathrm{s})+3 \mathrm{CO}(\mathrm{g})$} \\
\hline 298.15 & $1.00 \mathrm{E}+00$ & 4.425 & 2.977 & 0.005 & 1.448 & 0.67 & 911.40 & 0.000 & 2.977 \\
\hline 298.15 & $1.00 \mathrm{E}-01$ & 4.425 & 2.824 & 0.005 & 1.448 & 0.64 & 824.12 & 0.424 & 2.554 \\
\hline 298.15 & $1.00 \mathrm{E}-02$ & 4.425 & 2.671 & 0.006 & 1.448 & 0.60 & 752.10 & 0.773 & 2.204 \\
\hline 298.15 & $1.00 \mathrm{E}-03$ & 4.425 & 2.517 & 0.006 & 1.448 & 0.57 & 691.65 & 1.067 & 1.910 \\
\hline 298.15 & $1.00 \mathrm{E}-04$ & 4.425 & 2.364 & 0.007 & 1.448 & 0.53 & 640.20 & 1.317 & 1.660 \\
\hline 298.15 & $1.00 \mathrm{E}-05$ & 4.425 & 2.211 & 0.007 & 1.448 & 0.50 & 595.87 & 1.532 & 1.445 \\
\hline \multicolumn{10}{|c|}{$\mathrm{MgO}(\mathrm{s})+\mathrm{C}(\mathrm{s})=\mathrm{Mg}(\mathrm{g})+\mathrm{CO}(\mathrm{g})$} \\
\hline 298.15 & $1.00 \mathrm{E}+00$ & 26.253 & 22.408 & 0.013 & 3.844 & 0.85 & 2036.06 & 0.000 & 22.408 \\
\hline 298.15 & $1.00 \mathrm{E}-01$ & 26.253 & 21.939 & 0.014 & 3.844 & 0.84 & 1814.35 & 2.858 & 19.550 \\
\hline 298.15 & $1.00 \mathrm{E}-02$ & 26.253 & 21.469 & 0.016 & 3.844 & 0.82 & 1636.20 & 5.155 & 17.253 \\
\hline 298.15 & $1.00 \mathrm{E}-03$ & 26.253 & 20.999 & 0.018 & 3.844 & 0.80 & 1489.92 & 7.041 & 15.367 \\
\hline 298.15 & $1.00 \mathrm{E}-04$ & 26.253 & 20.530 & 0.019 & 3.844 & 0.78 & 1367.64 & 8.618 & 13.790 \\
\hline 298.15 & $1.00 \mathrm{E}-05$ & 26.253 & 20.060 & 0.021 & 3.844 & 0.76 & 1263.91 & 9.955 & 12.453 \\
\hline \multicolumn{10}{|c|}{$\mathrm{GeO}_{2}(\mathrm{~s})+2 \mathrm{C}(\mathrm{s})=\mathrm{Ge}(\mathrm{s})+2 \mathrm{CO}(\mathrm{g})$} \\
\hline 298.15 & $1.00 \mathrm{E}+00$ & 4.944 & 3.405 & 0.005 & 1.539 & 0.69 & 957.78 & 0.000 & 3.405 \\
\hline 298.15 & $1.00 \mathrm{E}-01$ & 4.944 & 3.248 & 0.006 & 1.539 & 0.66 & 869.02 & 0.458 & 2.947 \\
\hline 298.15 & $1.00 \mathrm{E}-02$ & 4.944 & 3.091 & 0.006 & 1.539 & 0.63 & 795.36 & 0.838 & 2.567 \\
\hline 298.15 & $1.00 \mathrm{E}-03$ & 4.944 & 2.934 & 0.007 & 1.539 & 0.59 & 733.17 & 1.159 & 2.246 \\
\hline 298.15 & $1.00 \mathrm{E}-04$ & 4.944 & 2.777 & 0.007 & 1.539 & 0.56 & 680.04 & 1.434 & 1.971 \\
\hline 298.15 & $1.00 \mathrm{E}-05$ & 4.944 & 2.619 & 0.008 & 1.539 & 0.53 & 634.05 & 1.671 & 1.734 \\
\hline \multicolumn{10}{|c|}{$\mathrm{H}_{2} \mathrm{O}(\mathrm{l})+\mathrm{C}(\mathrm{s})=\mathrm{H}_{2}(\mathrm{~g})+\mathrm{CO}(\mathrm{g})$} \\
\hline 298.15 & $1.00 \mathrm{E}+00$ & 86.961 & 49.627 & 0.125 & 37.334 & 0.57 & 694.48 & 0.000 & 49.627 \\
\hline 298.15 & $1.00 \mathrm{E}-01$ & 86.962 & 43.965 & 0.144 & 37.334 & 0.51 & 603.02 & 11.499 & 38.129 \\
\hline 298.15 & $1.00 \mathrm{E}-02$ & 86.962 & 38.302 & 0.163 & 37.334 & 0.44 & 532.84 & 20.321 & 29.307 \\
\hline 298.15 & $1.00 \mathrm{E}-03$ & 86.962 & 32.639 & 0.182 & 37.334 & 0.38 & 477.29 & 27.304 & 22.324 \\
\hline 298.15 & $1.00 \mathrm{E}-04$ & 86.962 & 26.976 & 0.201 & 37.334 & 0.31 & 432.23 & 32.969 & 16.660 \\
\hline 298.15 & $1.00 \mathrm{E}-05$ & 86.962 & 21.313 & 0.220 & 37.334 & 0.25 & 394.94 & 37.656 & 11.972 \\
\hline
\end{tabular}


Table 1 (Continued): Carbothermic Reduction of Metal oxides. All values are given per kg of produced metal. (*Note: At $T=2347 \mathrm{~K}$ and $P=1$ atm the produced Aluminum would be liquid rather than gaseous, however in order to have a uniform base for comparisons, a hypothetical gaseous final state was chosen, as at lower pressures Aluminum is gaseous ).

\begin{tabular}{|c|c|c|c|c|c|c|c|c|c|}
\hline $\mathbf{T}_{\mathbf{0}}$ & $\mathbf{P}$ & $\Delta \mathbf{H}^{(\mathbf{T o}, \mathbf{P})}$ & $\Delta G^{(\mathrm{To}, \mathbf{P})}$ & $\Delta \mathbf{S}^{\left(T_{0}, \mathbf{P}\right)}$ & $Q_{\text {irr }}{ }^{(T o, P o)}$ & $\lambda=\Delta G / \Delta H$ & $\mathbf{T}$ & $\mathbf{W}_{\mathbf{p}}^{(\mathrm{T}, \mathbf{P})}$ & $\mathbf{W}_{\mathbf{q}}^{(\mathbf{T}, \mathbf{P})}$ \\
\hline $\mathrm{K}$ & Atm & MJ & MJ & $\mathrm{MJ} / \mathrm{K}$ & MJ & & $\mathrm{K}$ & MJ & MJ \\
\hline \multicolumn{10}{|c|}{$\mathrm{ZnO}(\mathrm{l})+\mathrm{C}(\mathrm{s})=\mathrm{Zn}(\mathrm{g})+\mathrm{CO}(\mathrm{g})$} \\
\hline 298.15 & $1.00 \mathrm{E}+00$ & 4.833 & 3.534 & 0.004 & 1.299 & 0.73 & 1109.21 & 0.000 & 3.534 \\
\hline 298.15 & $1.00 \mathrm{E}-01$ & 4.833 & 3.359 & 0.005 & 1.299 & 0.70 & 977.79 & 0.573 & 2.961 \\
\hline 298.15 & $1.00 \mathrm{E}-02$ & 4.833 & 3.185 & 0.006 & 1.299 & 0.66 & 874.21 & 1.024 & 2.510 \\
\hline 298.15 & $1.00 \mathrm{E}-03$ & 4.833 & 3.010 & 0.006 & 1.299 & 0.62 & 790.47 & 1.389 & 2.145 \\
\hline 298.15 & $1.00 \mathrm{E}-04$ & 4.833 & 2.835 & 0.007 & 1.299 & 0.59 & 721.37 & 1.690 & 1.844 \\
\hline 298.15 & $1.00 \mathrm{E}-05$ & 4.833 & 2.661 & 0.007 & 1.299 & 0.55 & 663.38 & 1.943 & 1.591 \\
\hline \multicolumn{10}{|c|}{$\mathrm{Na}_{2} \mathrm{O}(\mathrm{s})+\mathrm{C}(\mathrm{s})=2 \mathrm{Na}(\mathrm{g})+\mathrm{CO}(\mathrm{g})$} \\
\hline 298.15 & $1.00 \mathrm{E}+00$ & 11.354 & 8.606 & 0.009 & 2.748 & 0.76 & 1231.66 & 0.000 & 8.606 \\
\hline 298.15 & $1.00 \mathrm{E}-01$ & 11.354 & 8.233 & 0.010 & 2.748 & 0.73 & 1084.70 & 1.355 & 7.251 \\
\hline 298.15 & $1.00 \mathrm{E}-02$ & 11.354 & 7.861 & 0.012 & 2.748 & 0.69 & 969.06 & 2.421 & 6.185 \\
\hline 298.15 & $1.00 \mathrm{E}-03$ & 11.354 & 7.488 & 0.013 & 2.748 & 0.66 & 875.71 & 3.282 & 5.324 \\
\hline 298.15 & $1.00 \mathrm{E}-04$ & 11.354 & 7.116 & 0.014 & 2.748 & 0.63 & 798.76 & 3.991 & 4.615 \\
\hline 298.15 & $1.00 \mathrm{E}-05$ & 11.354 & 6.744 & 0.015 & 2.748 & 0.59 & 734.23 & 4.586 & 4.020 \\
\hline \multicolumn{10}{|c|}{$\mathrm{NiO}(\mathrm{s})+\mathrm{C}(\mathrm{s})=\mathrm{Ni}(\mathrm{s})+\mathrm{CO}(\mathrm{g})$} \\
\hline 298.15 & $1.00 \mathrm{E}+00$ & 2.210 & 1.271 & 0.003 & 0.939 & 0.58 & 701.63 & 0.000 & 1.271 \\
\hline 298.15 & $1.00 \mathrm{E}-01$ & 2.210 & 1.174 & 0.003 & 0.939 & 0.53 & 635.83 & 0.207 & 1.064 \\
\hline 298.15 & $1.00 \mathrm{E}-02$ & 2.210 & 1.077 & 0.004 & 0.939 & 0.49 & 581.26 & 0.379 & 0.892 \\
\hline 298.15 & $1.00 \mathrm{E}-03$ & 2.210 & 0.979 & 0.004 & 0.939 & 0.44 & 535.36 & 0.524 & 0.747 \\
\hline 298.15 & $1.00 \mathrm{E}-04$ & 2.210 & 0.882 & 0.004 & 0.939 & 0.40 & 496.14 & 0.647 & 0.624 \\
\hline 298.15 & $1.00 \mathrm{E}-05$ & 2.210 & 0.785 & 0.005 & 0.939 & 0.36 & 462.31 & 0.754 & 0.517 \\
\hline \multicolumn{10}{|c|}{$\mathrm{CaO}(\mathrm{s})+\mathrm{C}(\mathrm{s})=\mathrm{Ca}(\mathrm{g})+\mathrm{CO}(\mathrm{g})$} \\
\hline 298.15 & $1.00 \mathrm{E}+00$ & 17.525 & 15.227 & 0.008 & 2.298 & 0.87 & 2274.23 & 0.000 & 15.227 \\
\hline 298.15 & $1.00 \mathrm{E}-01$ & 17.525 & 14.943 & 0.009 & 2.298 & 0.85 & 2023.34 & 1.933 & 13.294 \\
\hline 298.15 & $1.00 \mathrm{E}-02$ & 17.525 & 14.658 & 0.010 & 2.298 & 0.84 & 1822.36 & 3.482 & 11.746 \\
\hline 298.15 & $1.00 \mathrm{E}-03$ & 17.525 & 14.373 & 0.011 & 2.298 & 0.82 & 1657.70 & 4.751 & 10.476 \\
\hline 298.15 & $1.00 \mathrm{E}-04$ & 17.525 & 14.088 & 0.012 & 2.298 & 0.80 & 1520.29 & 5.810 & 9.418 \\
\hline 298.15 & $1.00 \mathrm{E}-05$ & 17.525 & 13.803 & 0.012 & 2.298 & 0.79 & 1403.95 & 6.706 & 8.521 \\
\hline \multicolumn{10}{|c|}{$\mathrm{PbO}(\mathrm{s})+\mathrm{C}(\mathrm{s})=\mathrm{Pb}(\mathrm{s})+\mathrm{CO}(\mathrm{g})$} \\
\hline 298.15 & $1.00 \mathrm{E}+00$ & 0.527 & 0.253 & 0.001 & 0.273 & 0.48 & 574.37 & 0.000 & 0.253 \\
\hline 298.15 & $1.00 \mathrm{E}-01$ & 0.527 & 0.226 & 0.001 & 0.273 & 0.43 & 521.69 & 0.048 & 0.205 \\
\hline 298.15 & $1.00 \mathrm{E}-02$ & 0.527 & 0.198 & 0.001 & 0.273 & 0.38 & 478.00 & 0.088 & 0.165 \\
\hline 298.15 & $1.00 \mathrm{E}-03$ & 0.527 & 0.171 & 0.001 & 0.273 & 0.32 & 441.07 & 0.122 & 0.131 \\
\hline 298.15 & $1.00 \mathrm{E}-04$ & 0.527 & 0.143 & 0.001 & 0.273 & 0.27 & 409.43 & 0.151 & 0.102 \\
\hline 298.15 & $1.00 \mathrm{E}-05$ & 0.527 & 0.116 & 0.001 & 0.273 & 0.22 & 382.03 & 0.176 & 0.077 \\
\hline \multicolumn{10}{|c|}{$\mathrm{SnO}_{2}(\mathrm{~s})+\mathrm{C}(\mathrm{s})=\mathrm{Sn}(\mathrm{l})+\mathrm{CO}(\mathrm{g})$} \\
\hline 298.15 & $1.00 \mathrm{E}+00$ & 3.083 & 2.093 & 0.003 & 0.990 & 0.68 & 928.30 & 0.000 & 2.093 \\
\hline 298.15 & $1.00 \mathrm{E}-01$ & 3.083 & 1.997 & 0.004 & 0.990 & 0.65 & 846.17 & 0.273 & 1.820 \\
\hline 298.15 & $1.00 \mathrm{E}-02$ & 3.083 & 1.900 & 0.004 & 0.990 & 0.62 & 777.32 & 0.501 & 1.591 \\
\hline 298.15 & $1.00 \mathrm{E}-03$ & 3.083 & 1.804 & 0.004 & 0.990 & 0.59 & 718.89 & 0.696 & 1.397 \\
\hline 298.15 & $1.00 \mathrm{E}-04$ & 3.083 & 1.708 & 0.005 & 0.990 & 0.55 & 668.59 & 0.863 & 1.230 \\
\hline 298.15 & $1.00 \mathrm{E}-05$ & 3.083 & 1.612 & 0.005 & 0.990 & 0.52 & 624.86 & 1.008 & 1.085 \\
\hline
\end{tabular}




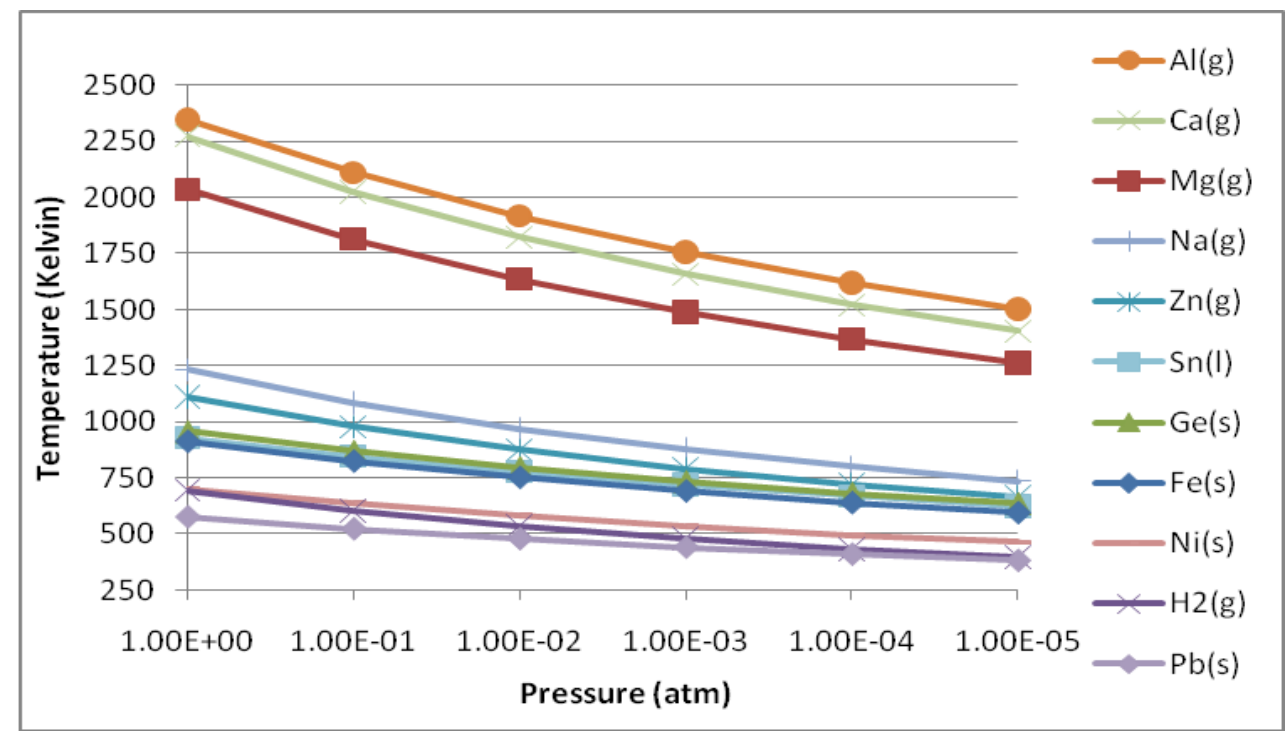

Figure 1: Temperatures of metal producing carbothermic reactions as described in Table 1.

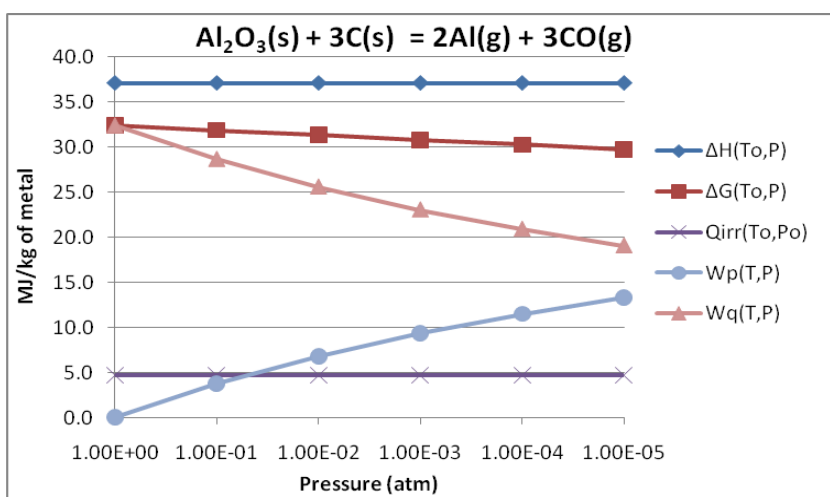

Figure 2: $\quad$ Pressure dependance of thermodynamic functions and ideally required work for the carbothermic reduction of $\mathrm{Al}_{2} \mathrm{O}_{3}$.

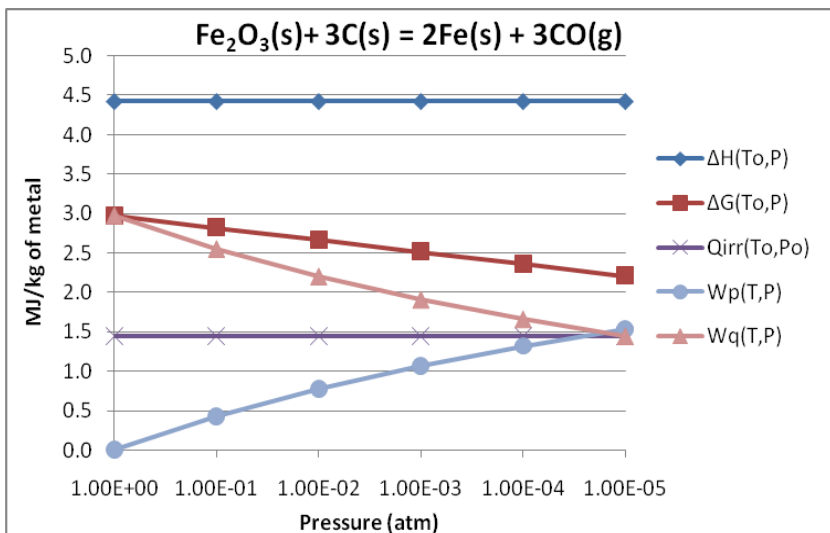

Figure 3: $\quad$ Pressure dependance of thermodynamic functions and ideally required work for the carbothermic reduction of $\mathrm{Fe}_{2} \mathrm{O}_{3}$.

From Figures 2 to 7 it is evident that as the temperature region of the carbothermic reduction is lowered (from $\mathrm{Al}$ to $\mathrm{H}_{2}$ ) the effect of the irreversible heat losses at $T_{0}\left(Q_{\text {irr }}\right)$ becomes important, while the total effect of the pumping work is more or less similar in all cases despite the fact that different amount of gases are evolved in each case. The

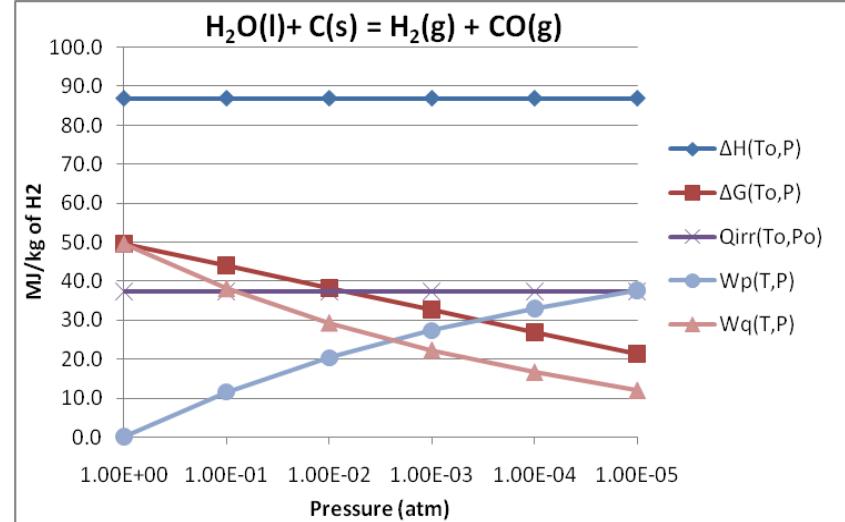

Figure 4: Pressure dependance of thermodynamic functions and ideally required work for the carbothermic reduction of $\mathrm{H}_{2} \mathrm{O}$.

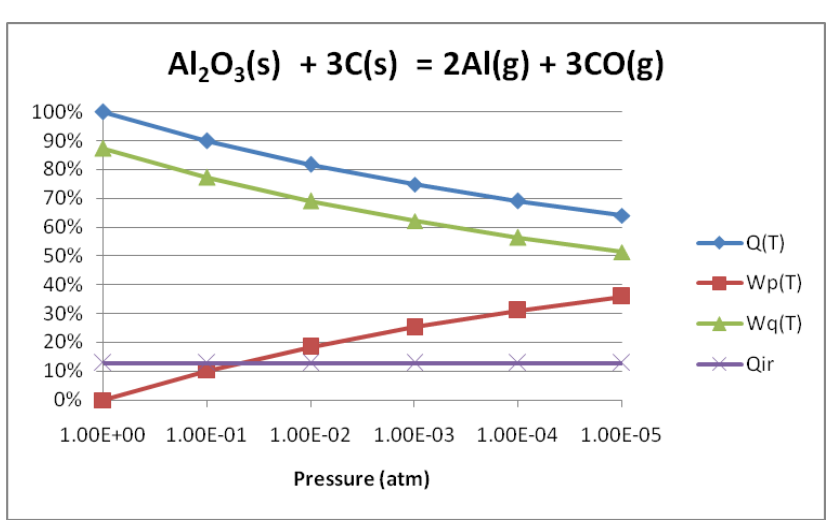

Figure 5: Pressure dependace of the ideal pumping work, chemical work, irrevirsible heat losses and total heat required in relation to reaction $\Delta H^{\circ}$ at atmospheric pressure, for the carbothermic reduction of $\mathrm{Al}_{2} \mathrm{O}_{3}$.

latter is verified in Figure 8 where the percentage of pumping work relative the whole energy required for the reaction $\left(\Delta \mathrm{H}^{\mathrm{o}}\right)$ is presented for all carbothermic reductions considered. 


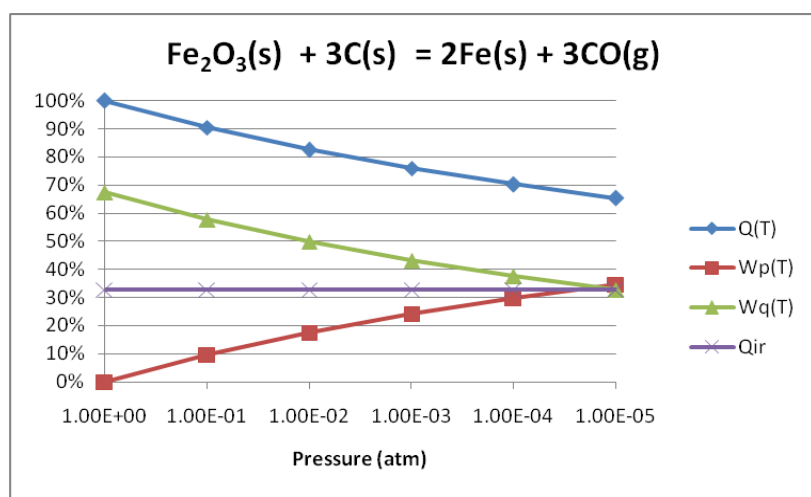

Figure 6: Pressure dependace of the ideal pumping work, chemical work, irrevirsible heat losses and total heat required in relation to reaction $\Delta H^{o}$ at atmospheric pressure, for the carbothermic reduction of $\mathrm{Fe}_{2} \mathrm{O}_{3}$.

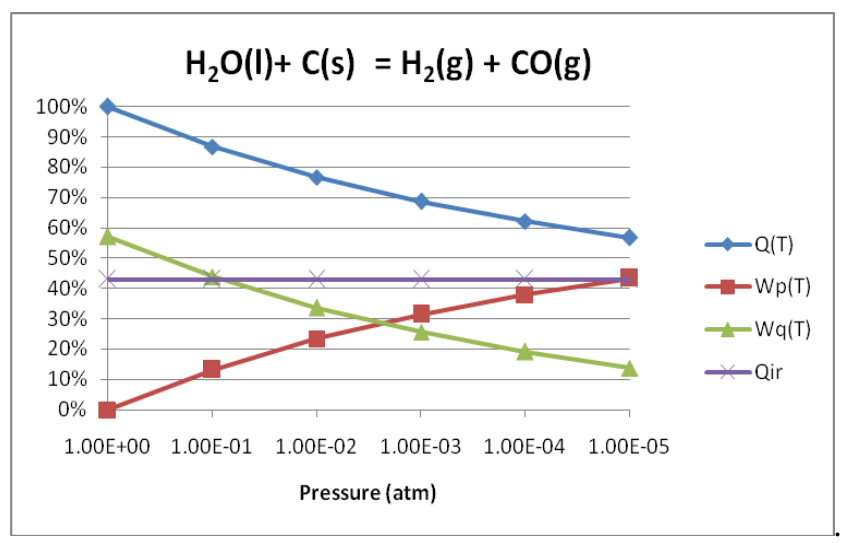

Figures 7: Pressure dependace of the ideal pumping work, chemical work, irrevirsible heat losses and total heat required in relation to reaction $\Delta H^{o}$ at atmospheric pressure, for the carbothermic reduction of $\mathrm{H}_{2} \mathrm{O}$

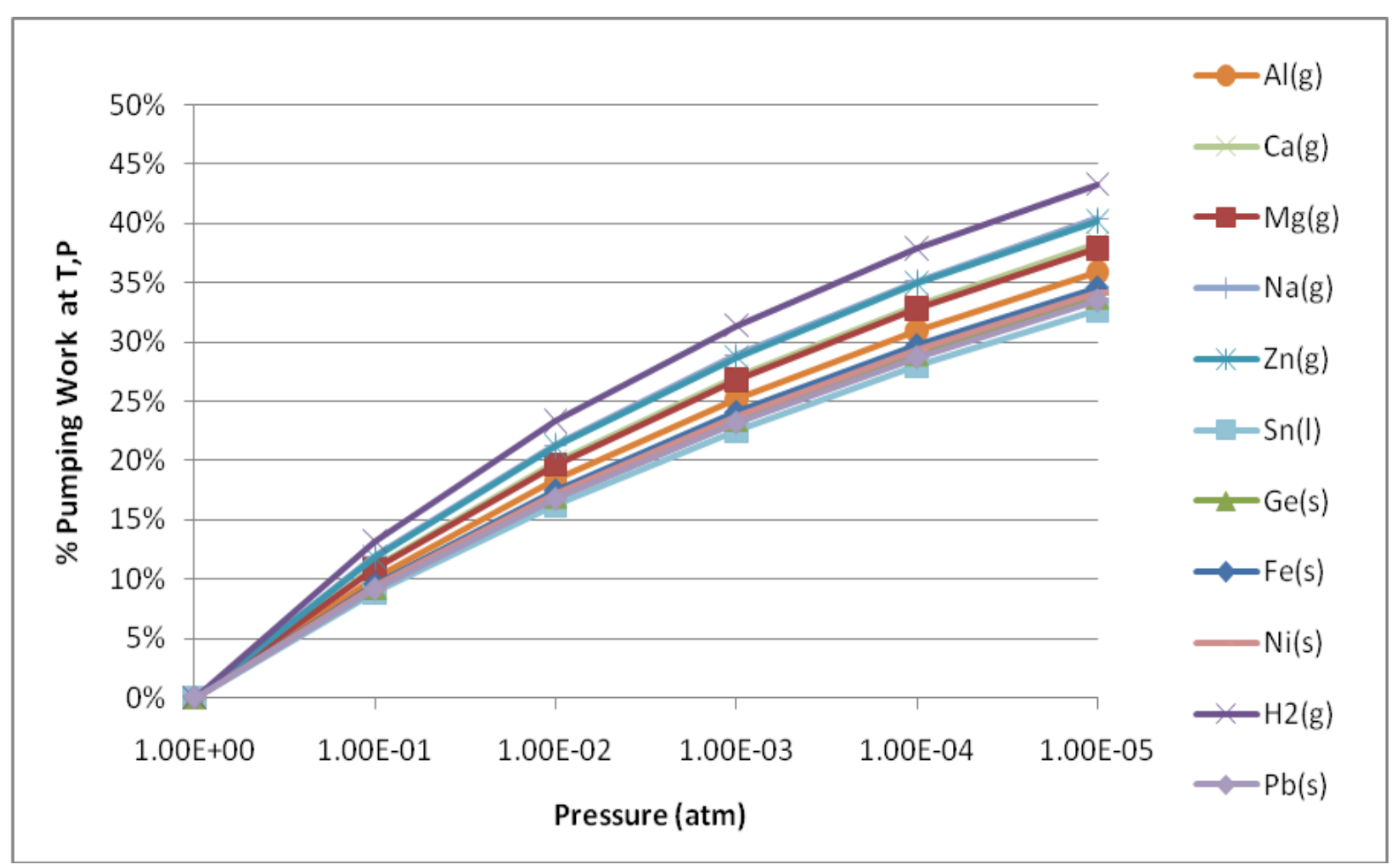

Figure 8: Relative pumping work needed for different metal production through carbothermic reduction under different pressures according to data of Table 1.

To assess the potential resource efficiency from conducting these reactions under vacuum it is now necessary to examine the exergy cost related with producing the needed pumping work $\mathrm{W}_{\mathrm{p}}$ and the overall heat supply $\left(\mathrm{Q}(\mathrm{T})=\mathrm{W}_{\mathrm{q}}(\mathrm{T})+\mathrm{Q}_{\text {irr }}\right)$. The pumping work industrially is produced through electrical (for the most part) or diesel burning vacuum pumps. Heating can be provided either through electric furnaces (resistance furnaces, inductive furnaces or Electric arc furnaces) through fossil fuel burning furnaces (calciners, rotary kilns, blast furnaces) or through solar furnaces utilizing concentrated solar radiation. Assuming all machines to be ideal (or to suffer from the same degree of imperfection) and disregarding diesel powered vacuum pumps which would be unsuitable for large scale industrial production, a comparison can be made between utilizing electrically powered vacuum pumps with different types of furnaces. Obviously the comparison of electrical pumping work coupled with electrical heating is pointless as the machines are assumed ideal and therefore the total sum of exergy spent is constantly the same. The same is not true when comparing a fossil fuel burning furnace coupled to an electrical vacuum pump. The electricity powering the vacuum pump is assumed to be produced in a fossil fuel burning power plant, utilizing the same fossil fuel as the above mentioned furnace. When this fossil fuel is coal, with a chemical exergy of $34.10 \mathrm{MJ} / \mathrm{kg}{ }^{\mathrm{b}}$, in the coal burning furnace it can be transformed fully into process heat while in the power plant it can be transformed only partially to electricity. Assuming an overall $40 \%$ thermal efficiency for transforming coal exergy to electricity, the exergy cost, calculated in kilograms of required coal, for the carbothermic reduction of alumina, hematite and water under different pressures are presented in Figures 9 to 11.

\footnotetext{
${ }^{b}$ The chemical exergy of coal is here equated with its Higher Heating Value (HHV) (Brodyansky,1994)
} 


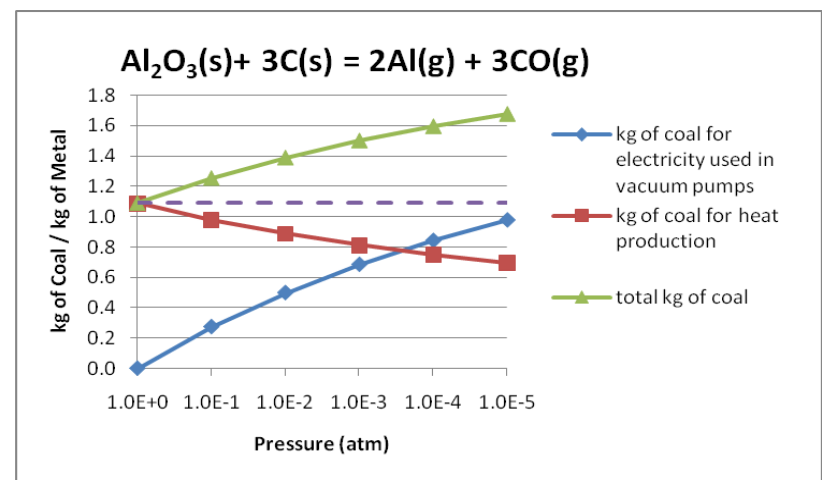

Figure 9: Exergy costs measured in $\mathrm{kg}$ of coal needed for process heating and electricity generation per $\mathrm{kg}$ of metal produced for the carbothermic reduction of $\mathrm{Al}_{2} \mathrm{O}_{3}$, under different pressures. The dashed line shows the $\mathrm{kg}$ of coal needed for providing enough process

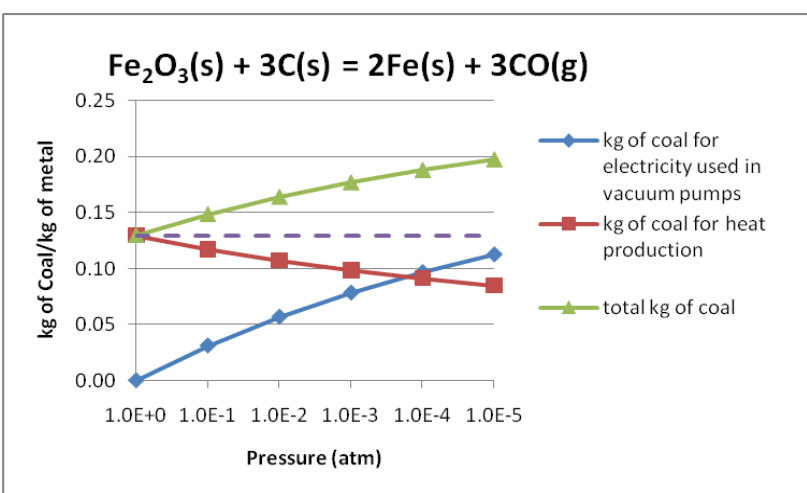

Figure 10: Exergy costs measured in kg of coal needed for process heating and electricity generation per $\mathrm{kg}$ of metal produced for the carbothermic reduction of $\mathrm{Fe}_{2} \mathrm{O}_{3}$ under different pressures. The dashed line shows the $\mathrm{kg}$ of coal needed for providing enough process

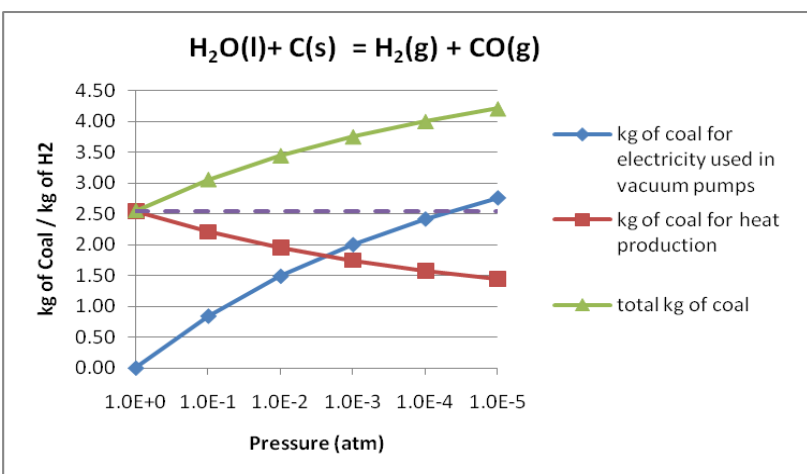

Figure 11: Exergy costs measured in $\mathrm{kg}$ of coal needed for process heating and electricity generation per $\mathrm{kg}$ of metal produced for the carbothermic reduction of $\mathrm{H}_{2} \mathrm{O}$ under different pressures. The dashed line shows the $\mathrm{kg}$ of coal needed for providing enough process heat for the carbothermic reduction to take place at atmospheric pressure.

As expected in all cases the total exergy/resource cost for producing heat and vacuum is higher than the cost of producing the heat of reaction at atmoshperic pressure (dashed lines in Figures 9-11). However based on these figures it is possible to estimate the potential of utilizing solar furances coupled with the electrically powered vacuum pumps, thereby providing heat through renewable sources and reducing the resource cost to that of powering only the vacuum pumps. If the later exergy cost (as $\mathrm{kg}$ of coal needed for their electricity) is less than the exergy cost needed to provide the heat of reaction at atmoshperic pressure through non-renewable sources (e.g. coal) then the process is more resource efficient. In Figure 12 the relative exergy cost of the pumping work ( $\mathrm{kg}$ of coal for $\mathrm{Wp} / \mathrm{kg}$ of coal for $\Delta \mathrm{H}^{\mathrm{o}}$ heat at $\mathrm{T}_{\mathrm{o}}, \mathrm{P}_{\mathrm{o}}$ ) is presented for all reactions considered, while in Figure 13 this exergy cost is ploted against the temperature that must be achieved in the solar furnace for the reaction to take place under the relative vacuum.

As seen in Figure 12 at low pressures $\left(\mathrm{P}<10^{-5}\right.$ atm) the exergy gains from utilizing solar furnaces are relatively small (20\% or less), but on the other hand as seen in Figure 13 for the high temperatures carbothermic reductions ( $\mathrm{Al}$, $\mathrm{Ca}, \mathrm{Mg}$ ) the reduction in the temperature of furnace operation is quite large. The same is not true for the moderate and low temperature carbothermic reductions, where the exergy spent for vacuum has a much smaller effect in the reaction temperature decrease and it would be theoretically better to simply supply all the reaction heat needed at atmospheric pressure.

\section{Conclusions}

A basic thermodynamic analysis can be used to predict the effect of pressure decrease on the temperature and exergy cost of a reaction with gaseous products. Such reactions with significant industrial interest are the carbothermic reductions of metal oxides, which can be divided into high, moderate and low temperature reductions based on the relative reaction temperature. The energy analysis of 11 different metal producing carbothermic reductions revealed that the pumping work substitutes relatively the same amount of heat in all 11 reactions, despite the fact that the volume of gases evolved in each case differs significantly. The exergy analysis for conducting these reactions with non-renewable resources showed that due to the high exergy cost of fossil fuel generated electricity the application of vacuum would increase the overall exergy cost of these reductions. On the other hand, if the heat needed for the reactions could be produced through renewable resources, such as concentrated solar radiation, then the use of vacuum would have a positive effect in the cases of high temperature reductions where a significant decrease in reaction temperature is observed as more exergy is spent in pumping work. Therefore one could conclude that vacuum metallurgy has a potential of being coupled with future solar furnace technology in a effort primarily to limit the temperature of operation for high temperature reactions. If for example a vacuum between $10^{-3}$ to $10^{-4}$ atm is applied then the carbothermic reduction of $\mathrm{Al}_{2} \mathrm{O}_{3}, \mathrm{CaO}$ and $\mathrm{MgO}$ can be achieved at temperatures between 1750 to $1500 \mathrm{~K}$ with a total exergy cost of $60 \%$ to $80 \%$ of the total reaction enthalpy. However, under ideal conditions and maximum efficiency for concentrating solar radiation, one would need a mean solar flux concentrations of 5000 suns to achieve $1500 \mathrm{~K}$ and 10000 suns to achieve $1700 \mathrm{~K}$ (Steinfeld and Palumbo, 2001). Modern day solar tower facilities can achieve concentrations between 500 to 5000 suns, while solar dish systems can achieve concentration between 1000 to 10000 suns. Thus while it is theoretically possible to achieve such temperatures and perform high temperature reductions at lower exergy cost by utilizing solar radiation it is obvious that in practice this can only be achieved at the limit of the current state-of-the-art solar technology. 


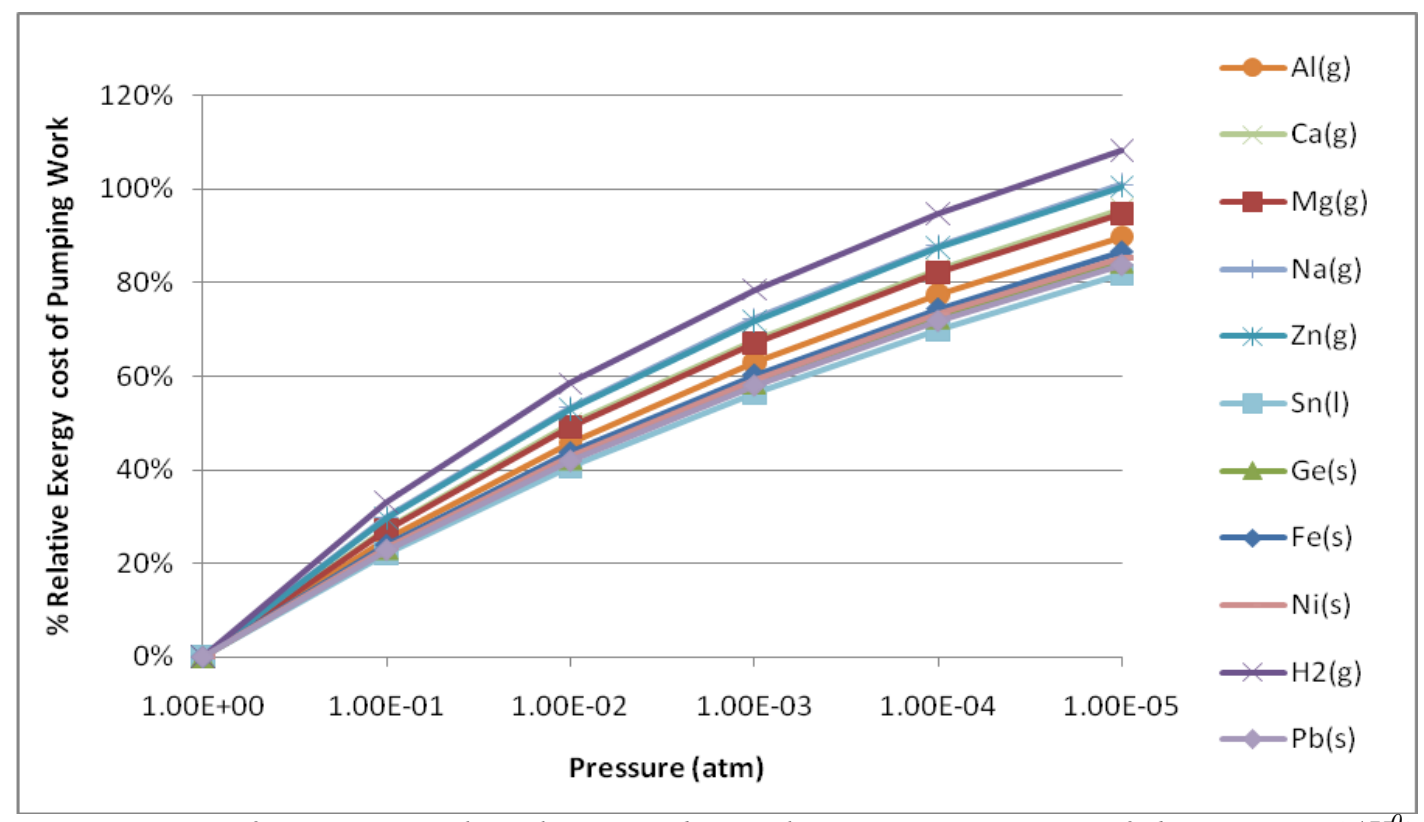

Figure 12: Exergy cost of pumping work relative to the total energy requirement of the reaction $\left(\Delta H^{0}\right)$ for all the carbrothermic reductions considered in Table 1.

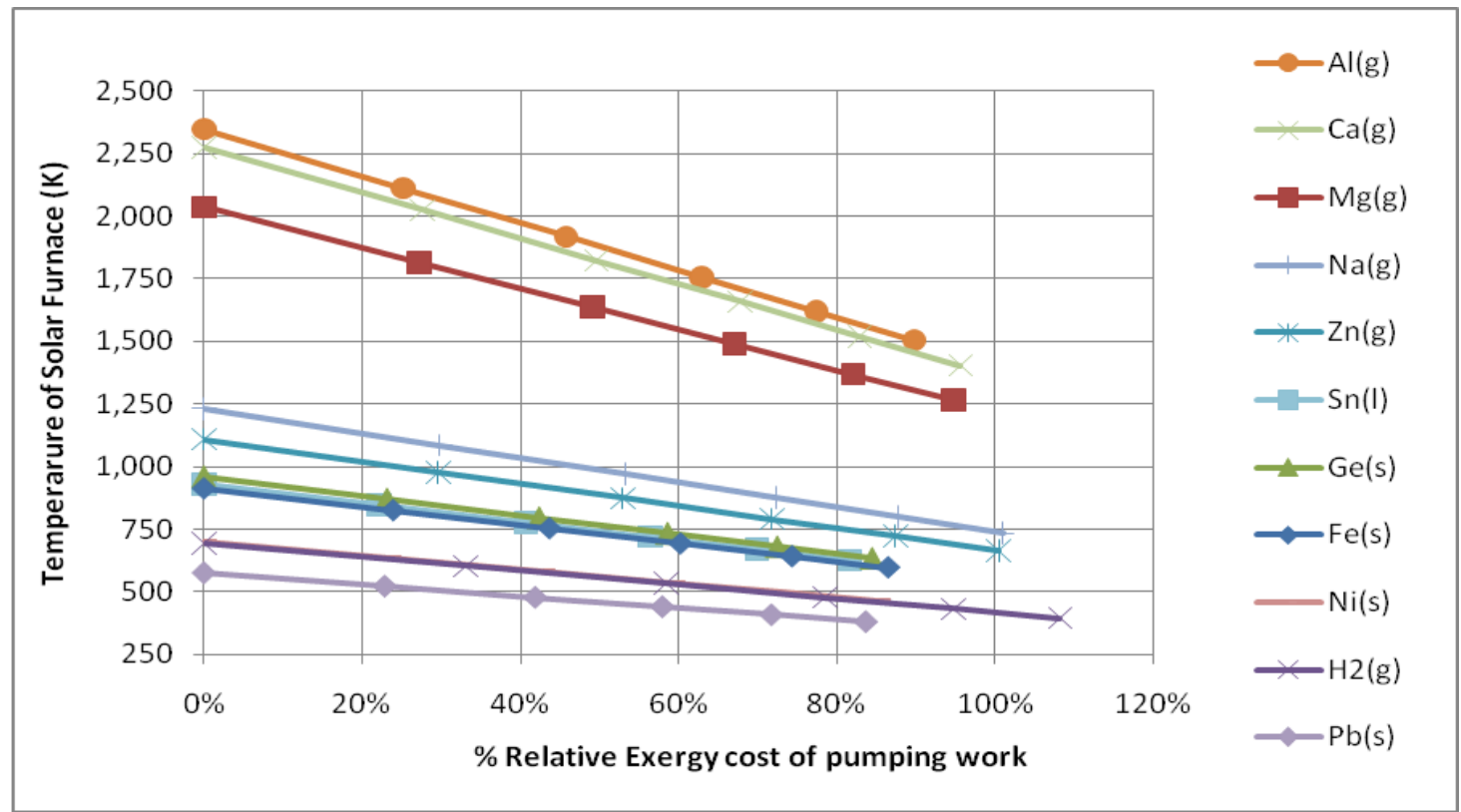

Figure 13: Reaction temperature decrease in relation to the relative exergy cost of pumping work (Figure 6) needed for all the carbrothermic reductions considered in Table 1.

\section{Acknowledgements}

The research leading to these results has received funding from the European Union Seventh Framework Programme ([FP7/2007-2013]) under grant agreement $\mathrm{n}^{\circ}$ ENER/FP7EN/249710/ENEXAL

\section{References}

Brodyansky, V. M. (ed) (1994), The Efficiency of Industrial Processes: Exergy Analysis and Optimization, Amsterdam: Elsevier Science \& Technology Books.

Kroll W.J. (1951), Vacuum Metallurgy its characteristics and its slope, Vacuum 1, 163-184.

Kruesi M., Galvez M.E., Halmann M., Steinfeld A. (2011), Solar Aluminum Production by Vacuum Carbothermal
Reduction of Alumina - Thermodynamic and Experimental Analyses, Metallurgical and Materials Transactions B 42, 254-260.

Murray J.P., Steinfeld A., Fletcher E.A. (1995), Metals, Nitrides and Carbides via solar carbothermal reduction of metal oxides, Energy 20(7), pp.695-704.

Sato N. (2004), Chemical Energy and Exergy: An introduction to chemical thermodynamics for engineers, Amsterdam: Elsevier Science \& Technology Books.

Steinfeld A., Palumbo R. (2001), Solar thermochemical process technology, in Encyclopedia of Physical Science and Technology, R. A. Meyers, ed., Academic Press, 15, pp. 237-256. 